\title{
ON THE GENERALIZED HYERS-ULAM STABILITY OF SWIATAK'S FUNCTIONAL EQUATION
}

\author{
BOUIKHALENE BELAID, ElQORACHI ELHOUCIEN \\ AND THEMISTOCLES M. RASSIAS
}

Abstract. In this paper we shall study the generalized Hyers-Ulam stability of Swiatak's functional equation

$$
f(x+y)+f(x-y)=2 f(x)+2 f(y)+g(x) g(y), \quad x, y \in G,
$$

where $G$ is an abelian group and $f, g: G \longrightarrow \mathbb{C}$ are complex-valued functions satisfying the condition $g(e) \neq 0$.

Mathematics subject classification (2000): 39B82, 39B52.

Key words and phrases: Functional equations, Hyers-Ulam-Rassias stability.

\section{REFERENCES}

[1] AOKI T., On the stability of the linear transformation in Banach spaces, J. Math. Soc. Japan, 2 (1950), 64-66.

[2] Bouikhalene B., ElQORAChi E., AND Redounini A., On Hyers-Ulam stability of a special case of O'Connor's and Gajda's functional equations, JIMPA, J. Inequal. Pure Appli. 6 no. 2 (2005), Article 32.

[3] Bourgin D. J., Class of transformations and bordering transformations, Bull. Amer. Math. Soc. 57 (1951), 223-237.

[4] Cholewa P. W., Remarks on the stability of functional equtaions, Aequationes Math. 27 (1984), 76-86.

[5] Chung J. K., Ebanks B. R., NG C. T. And SAHOo P. K., On a quadratic-trigonometric functional equation and some applications, Trans. Amer. Math. Soc. 347 (1995), 1131-1161.

[6] FEnYÖ I., Osservazioni su Alcuni teoremi di D. H. Hyers, Istit Lombardo Accad. Sci. Lett. Rend. A 114 (1980), 235-242.

[7] FenYö I., On an inequality of P. W. Cholewa, in: General Inequalities, 5, Internat. Schriftenreiche Numer, Math, Vol. 80, Birkhäuser, Basel, (1987), pp. 277-280.

[8] FORTI G. L., Hyers-Ulam stability of functional equations in several variables, Aequationes Math. 50 (1995), 143-190.

[9] GAJDA Z. AND GER R., Subadditive multifunctions and Hyers-Ulam stability, in: General Inequalities, 5, Internat. Schriftenreiche Numer. Math. Vol. 80, Birkhäuser, Basel, (1987).

[10] GAJDA Z., On stability of additive mappings, Internat. J. Math. Sci. 14 (1991), 431-434.

[11] HYERS D. H., On the stability of the linear functional equation, Proc. Nat. Acad. Sci. U.S.A. 27 (1941), 222-224.

[12] HYERS D. H., The stability of homomorphisms and related topics, in: Global Analysis-Analysis on Manifolds, (ed. Th. M. Rassias), Teubner-Texte Math. 75 (1983), pp. 140-153.

[13] Hyers D. H. And Rassias TH. M., Approximate homomorphisms, Aequationes Math., 44 (1992), $125-153$.

[14] Hyers D. H., IsAC, G. And Rassias Th. M., Stability of Functional Equations in Several Variables, Birkhäuser, Basel, 1998.

[15] JUN K.-W. AND LEE Y.-H., On the Hyers-Ulam-Rassias stability of a Pexiderized quadratic inequality, Math. Inequal. and Appli. 4(1) (2001), 93-118. 
[16] JUNG S.-M., Hyers-Ulam-Rassias Stability of Functional Equations in Mathematical Analysis, Hadronic Press, Inc., Palm Harbor, Florida, 2003.

[17] Rassias TH. M., On the stability of linear mappings in Banach spaces, Proc. Amer. Math. Soc. 72 (1978), 297-300.

[18] RASSIAS TH. M., The problem of S. M. Ulam for approximately multiplicative mappings, J. Math. Anal. Appl. 246 (2000), 352-378.

[19] RASSIAS TH. M., On the stability of the functional equations and a problem of Ulam, Acta Applicandae Math. 62 (2000), 23-130.

[20] SCHWAIgER J., The functional equation of homogeneity and its stability properties, Österreich. Akad. Wiss. Math.-Natur, Kl, Sitzungsber. Abt. II (1996), 205, 3-12.

[21] SKоF F., Local proporeties and approximations of operators, Rend. Sem. Math. Fis. Milano 53 (1983), 113-129.

[22] SWIATAK H., On two functional equations connected with the equation $\phi(x+y)+\phi(x-y)=$ $2 \phi(x)+2 \phi(y)$, Aequationes Math. 5 (1970), 3-9.

[23] SzÉKELYHIDI L., On a theorem of Baker, Lawrence, and Zorzitto, Proc. Amer. Math. Soc. 84 (1982), 95-96.

[24] SZÉKELYHIDI L., On a stability theorem, C. R. Math. Rep. Acad. Sci. Canada 3 (1981), 253-255.

[25] SZÉKELYHIDI L., The stability of d'Alembert-type functional equations, Acta Sci. Math. (Szeged) 44 (1982), 313-320.

[26] SZÉKELYHIDI L., The stability of the sine and cosine functional equations, Proc. Amer. Math. Soc. 110 (1990), 109-115.

[27] Ulam S. M., A Collection of Mathematical Problems, Interscience Publ. New York, 1961, Problems in Modern Mathematics, Wiley, New York, 1964. 